\title{
Learning-Centered Teaching And Backward Course Design - From Transferring Knowledge To Teaching Skills
}

\author{
Nitza Davidovitch, Ariel University, Israel
}

\begin{abstract}
The article shall focus on the design of academic courses from a learning-centered approach, with an emphasis on the formulation of learning outcomes. Planning a course from a learning-centered approach helps create a dialogue between the academic faculty and students and creates congruence between learning outcomes (course goals) and instruction methods and assessment goals. The purpose of the article is to present the need for paradigmatic change and for a transition from planning content-centered courses to planning learning-centered courses. The need for paradigmatic change stems from technological transformations and from the status of knowledge as belonging to everyone. The article presents the significance of expressing learning outcomes in writing and the advantages and challenges of formulating learning aims. The article shall present a case study of a course in the "backward design" method that is consistent with the learning-centered paradigm. The challenges formed by this method will be discussed as well.
\end{abstract}

Keywords: Learning Outcomes; Course Design; Knowledge; Teaching Skills

\section{INTRODUCTION}

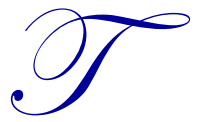

he monopoly on knowledge was breached in the $21^{\text {st }}$ century. Throughout the existence of mankind knowledge always equaled power. Every revolution, for example the invention of writing, the invention of print, or social revolutions, such as teaching literacy to the masses, resulted in a change in the balance of powers (for a wider discussion see Harari, 2006). The introduction of internet in modern households worldwide had the same effect as the invention of print on medieval society - it made knowledge accessible and available to everyone. In order to enjoy print, one had to be able to read. In order to enjoy using the worldwide web, one must be able to operate a computer. Once this basic condition exists, technology is open to all and the sky is the limit. Technology is usually created in an attempt to fulfill a need of society, but technology itself often changes the very society that it was intended to serve.

The internet that entered our life recently has changed it fundamentally - the speed, the ease, the accessibility of information "shrunk" the global village and transformed it into a mere "neighborhood". People from all over the world are a click away from each other; information has become readily available and swift. What previously required hours of book search is now a keyword away. The internet, as a medium, has many features and endless functions for utilization - sales promotion, information seeking, remote operation, and more. The internet makes it possible to expand and control the generation, transmittal, reception, duplication, and retrieval of information and it offers a wide variety of contents, styles, and forms of communication (Shinar, 2001).

Any technology that enters our life leads to the development of new behavior patterns. As in the popular saying "the medium is the message", the message of each medium or technology is manifested by changing the scope or pace of the previous behavior pattern. The power that shapes the media is the media itself, including the internet, which has made it possible to carry out the vision of the global village in practice (McLuhan, 1964, in Caspi, 1995). 
The internet, as a technology located in almost every home in the Western world, is perceived as a dominant and contemporary medium. This dominant medium shapes society, both on the individual and on the collective level. It determines whether the government is centralized or decentralized, how we communicate with people, how we think (rationally or interactively). This impact has implications for all our spheres of life in a deterministic, one-sided process (Davis, 1999).

As early as the beginning of the twentieth century, various scholars were already debating the effects of technology on society and culture. Freud claimed that technical and scientific progress should not be disregarded and that the effect of these improvements on our life merits attention. Freud was joined by other theorists who claimed that, as a society, we should be attentive when accepting a new technology into our culture as from the moment it is permitted access, it won't stop until it reaches its full potential. Thus, we must take into consideration that radical technologies create new definitions of old terms and that this process occurs without our being fully aware of it. The new technologies introduce new terms into the language and change everything we formerly understood (Postman, 1993).

In fact, the invention of the internet reshaped the world we live in and created new possibilities for defining concepts such as the public domain, reality, globalization, and communal affiliation. Gradually, more parts of the world became interrelated, and today it is known as a global community. Individual freedom of movement is significantly expressed in virtual space through the media and particularly thanks to the internet. Recently, in particular, there has been an increase in the rate of generation and distribution of contents and information in the electronic network in various topics and disciplines (Shinar, 2001). Computerized technology gives internet users access to information and social activities with the purpose of fulfilling their needs and improving their life style and, thus since the mid-1990s, billions of people all over the world have been able to access information from any place unlimited by space or time (see Internet World Stats, 2013). The internet has realized the vision of the global village through its innovative technology and the information transmitted in the virtual space is diverse; for example, real-time news updates, reading newspapers from all over the world, ordering various services from home, playing online games with other users, and contacting other users on forums and in virtual communities (Barak \& King, 2000).

Academe, responsible for creating new information in modern society, has gone through a series of changes as well. Technological inventions, such as the personal computer (Kulik, Kulik \& Cohen, 1980), the worldwide web (BrckaLorenz, Haeger, Nailos \& Rabourn, 2013; Jones, 2002), the transition to distance learning (Phipps \& Merisotis, 1999), and the drastic rise in the number of academic students, are some of the factors behind these changes. Despite the transformations in the world of higher education, there have been only few changes in learning strategies and instruction methods (Reynolds, 2000), notwithstanding the use and acceptance of new technologies (McKeachie, 1990).

Despite the enormous change in the status and accessibility of knowledge, particularly among students of higher education who frequently use technology for learning (BrckaLorenz et al., 2013), teaching methods have remained static and still focus on the transfer of knowledge (Eberly, Newton \& Wiggins, 2010). This fact is fairly problematic as the extensive use of technology in higher education is not necessarily contributing to learning or teaching (Kazley et al., 2013). Namely, the academic environment has indeed changed as a result of technology, but contemporary teaching methods (aside from effects facilitated by computers) have not changed.

Consequently, questions often arise concerning the value of academic degrees and the quality of learning in academic classrooms (Stage \& Muller, 1999), considering the steady focus on transferring knowledge. Many instructors still think that they can transfer their knowledge in a complete form to students' minds (Cross, 2000). This is not only impossible; rather, in the information era, it is an anachronistic approach that renders the instructor irrelevant. Students often ask themselves why they should make an effort to come to class when all the material appears on the course website or is freely accessible on the internet. Such questions indeed hint at the added value that instructors can give students beyond the transfer of knowledge.

Such questions are legitimate today more than ever and challenge the traditional paradigm of "teachingcentered learning". Most of us have been exposed throughout life to this approach that sees academic studies as a 
place where teaching is transferred through the study program (Barr \& Tagg, 1995). In a typical course, teaching is transferred and constructed according to the number of lessons (50-minute lectures and three credits), with the aim of covering the contents of the course and concluding with a final assignment that serves as a means of assessment (Reynold, 2000). In the traditional teaching method, "teachers decide for the learner what is required from outside by defining characteristics of instruction, curriculum, assessment, and management to achieve desired learning outcomes" (Wagner \& McCombs, 1995, p. 32).

As a result of the learner's passivity in traditional teaching, students are accountable for their learning process. They sit in their place, move from room to room, from course to course, play with their cellular phones, occasionally utter a comment in class, go on Facebook, open their laptops, and close their laptops. Eventually they complete the course (hopefully) with a little more knowledge, but no different than when they began. Students who learn in the traditional approach do not gain skills and, in this context, it has been said that acquiring a Bachelor's degree can be considered a hollow achievement if one has not acquired, in the process, skills and capabilities suitable for the $21^{\text {st }}$ century (Kuh, Kinzie, Schuh \& Whitt, 2010, p. ix). The purpose of the current article is to present a different approach to teaching while imparting applied tools for a transition from "teaching centered learning" to "learning-centered teaching".

\section{LEARNING-CENTERED TEACHING}

Learning-centered teaching is a new-old educational paradigm (Seel, 2003) that has its roots in the rise of the progressive education movement in late $19^{\text {th }}$ century US. This approach is based on the principle that knowledge cannot be transferred to learners in its complete form, rather by causing learners to discover or acquire knowledge independently (Rogoff, 1994). This is a shift from the traditional approach that sees learning as a process of passive knowledge reception from a figure of authority to a learning-centered approach that sees learning as an active process in which learners go through a process of change (Gehart, 2011). While in the traditional approach, the emphasis is on the scope and nature of contents learned, in the learning-centered approach, the emphasis is on the nature of the learner's process. According to this outlook, learning is a variety of activities and programs that challenge students and give them an opportunity to grow (King \& Anderson, 2004). Growth occurs when students undergo a series of changes that lead them to more complex behavior, enabling them to cope with changing life challenges (Kuh et al., 1991). This approach is based on the premise that what students do is more important that what they learn in their undergraduate studies (Kuh et al., 2010, p. 8).

The research literature shows that this approach indeed promotes higher quality learning. For example, a study examining the effect of learning-centered teaching versus instruction-centered teaching on the attitudes and knowledge of statistics, students (Harpe, Phipps \& Alowayesh, 2012) found that students in the learning-centered approach were more knowledgeable and had more positive attitudes toward their learning environment. Students in the learning-centered approach reported having more opportunities to use their knowledge and feeling more in control of their grades. Nonetheless, despite the data supporting the learning-centered approach, most schools of higher education continue to treat information transfer as the most important value of teaching. Eberly, Newton and Wiggins (2001) analyzed 145 syllabuses of various general undergraduate courses. Their thematic analysis found that $50 \%$ of syllabus themes dealt with administration (course format, course contents, and use of technology) and $75 \%$ of the themes emphasized course development (basic information about the course, reading requirements, course contents, methods of assessment, and use of technology). Only one theme in all the syllabuses examined dealt with the interpersonal realm (accountability for learning). The researchers concluded that the main emphasis in courses is on transferring information, while the topic of developing skills or attitudes, as part of learning, receives almost no attention. They claim that the syllabus, as a meaningful tool in the learning process, must reflect and formulate the goals of the degree as well as the goals of the course. 
Table 1 is a portrayal of the learning paradigm that follows the emerging approach versus the instruction paradigm that follows the traditional approach (from Barr \& Tagg, 1995).

Table 1: Teaching and Learning Paradigms

\begin{tabular}{|c|c|}
\hline The Learning Paradigm & The Instruction Paradigm \\
\hline \multicolumn{2}{|c|}{ Mission and Purposes } \\
\hline Produce learning & Provide/deliver instruction \\
\hline Elicit students' discovery and construction of knowledge & Transfer knowledge from faculty to students \\
\hline Create powerful learning environments & Offer courses and programs \\
\hline Improve the quality of learning & Improve the quality of instruction \\
\hline Achieve success for diverse students & Achieve access for diverse students \\
\hline \multicolumn{2}{|c|}{ Criteria for Success } \\
\hline Learning and student-success outcomes & Inputs, resources \\
\hline Quality of exiting students & Quality of entering students \\
\hline Learning technologies development & Curriculum development, expansion \\
\hline Quantity and quality of outcomes & Quantity and quality of resources \\
\hline Aggregate learning growth, efficiency & Enrollment, revenue growth \\
\hline Quality of students, learning & Quality of faculty, instruction \\
\hline \multicolumn{2}{|c|}{ Teaching/Learning Structures } \\
\hline Holistic; whole prior to parts & Parts prior to whole \\
\hline Learning held constant, time varies & Time held constant, learning varies \\
\hline Learning environments & 50 minute lecture, 3 -unit course \\
\hline Environment ready when student is & Classes start/end at same time \\
\hline Whatever learning experience works & One teacher, one classroom \\
\hline Cross discipline/department & Independent disciplines / departments \\
\hline Specified learning results & Covering material \\
\hline External evaluations of learning & End-of-course assessment \\
\hline Public assessment & Private assessment \\
\hline Degree equals demonstrated knowledge and skills & Degree equals accumulated credit hours \\
\hline \multicolumn{2}{|c|}{ Learning Theory } \\
\hline $\begin{array}{l}\text { Knowledge exists in each person's mind and is shaped by } \\
\text { individual experience }\end{array}$ & Knowledge exists "out there" \\
\hline Knowledge is constructed, created & $\begin{array}{l}\text { Knowledge comes in chunks and bits; delivered by instructors, } \\
\text { absorbed by students }\end{array}$ \\
\hline Learning is a nesting and interacting of frameworks & Leaning is cumulative and linear \\
\hline Learning is student-centered and controlled & Learning is teacher centered and controlled \\
\hline $\begin{array}{l}\text { Learning environments and learning are cooperative and } \\
\text { supportive }\end{array}$ & The learning environment is competitive and individualistic \\
\hline
\end{tabular}

\section{ABOUT BACKWARD COURSE DESIGN}

Constructing courses in a backward design is based on the premise that teachers must clarify to students unequivocally what they are expected to learn, do, and understand by the end of the lecture or course. Backward course design forces instructors to move the focus of course design from course contents to outcomes. Such a design makes it possible for instructors to answer the question often asked by students: "Why are we doing this assignment? What is its purpose and will I ever use it in real life?" (Daugherty, 2006) Backward design answers three questions:

- What will the student know and be able to do, in general, by the end of the course, independent of the activities and texts used?

- What evidence is there of such abilities?

- Which texts, activities, and methods will best serve the desired results?

This approach was originally derived from the scientific educational disciplines called STEM (Science, Technology, Engineering, and Mathematics) and derives from the endpoint; namely, what are the desired results, what outcomes do we expect of the course? (Wiggins \& McTighe, 2005) STEM disciplines were the first to embrace this approach and the purpose of the course became the starting point of course design (Streveler, Smith \& Pilotte, 
2012). Courses were planned in four stages and instructors were required to map desired outcomes, assessment methods, and teaching strategies, as accurately as possible.

\section{Stage A: Formulating Student-Centered Large Goals}

- What do you expect the graduate to know and be able to do?

- What do you expect the student to know and be able to do upon completing the course/unit? (in regard to skills, knowledge, capabilities, perceptions, values)

1. What is the big idea? What effect will this course have on students' life by the end of the course? In a few years?

2. What are the practical expectations of course graduates?

a. Ability to apply knowledge in mathematics, science, and engineering

b. Ability to plan and conduct experiments

c. Ability to analyze and interpret data

d. Ability to plan a system, component, or process in a way that answers requirements with consideration of realistic constraints (financial, environmental, social, political, ethical constraints)

e. Ability to function in multidisciplinary teams

f. Ability to identify, formulate, and solve engineering problems

g. Understanding of professional and ethical responsibility

h. Ability to efficiently impart the wide education necessary in order to understand the effect of engineering solutions in the global, economic, environmental, and social context

i. Recognition of the need and ability to engage in learning throughout life

j. Knowledge of contemporary issues

k. Ability to use modern engineering methods, capabilities, and tools essential for engineering work

\section{Stage B: Formulating Operative (Executive) Aims Resulting From the Large Goals}

The formulation shall take the form of 3-5 behavioral aims and shall list anticipated academic outcomes from the perspective of learners. For example, by the end of the course, the student shall be able to:

- $\quad$ Identify and solve numerical problems

- $\quad$ Choose the most appropriate numerical method for solving a problem according to its characteristics

- Understand the characteristics of the method and correctly interpret results

Stage C: Choosing Assessment Methods (for Measuring Achievement of Teaching Goals) and Setting Criteria for Assessing Performance: How Can Students Demonstrate That They Know and Are Capable of Doing What is Expressed in the Goals?

\footnotetext{
- Written exams and quizzes

- Oral exams

- $\quad$ Open or closed-ended (multi-choice) exams

- $\quad$ Authentic assignments

- Individual home assignments

- $\quad$ Group home assignments / projects

- Individual or group project presentations in class

- $\quad$ Peer assessment

- $\quad$ Self assessment
} 
Stage D: Choosing Teaching Methods/Strategies for Achieving Aims: What Will You Do in Your Teaching so That Students can Achieve the Aims you Formulated?

- $\quad$ Format

1. Lectures

2. Seminar

3. Exercises

4. Laboratories/studios

- $\quad$ Activities

1. Discussions

2. Demonstrations

3. Practice/coaching

4. Work in pairs/groups/collectively

5. Learning based on case studies/problem-solving

6. Technology-supported learning

In each method, secondary aims should be listed as well as practical learning experiences that will be included in each teaching method. For example, if the goal of instruction is to help students develop skills, both in teamwork and individual work through teaching and learning methods, teaching methods for achieving the secondary aims of this goal are:

- In order to learn how to work in a team, teamwork is essential.

- In order to learn to communicate, assignments on communication problems should be given.

- In order to learn to be accountable for their learning, students will be required to learn on their own how to solve assignments.

- In order to learn ethical, social, professional, and environmental aspects related to the discipline, appropriate examples for demonstration or discussion should be included.

\section{Stage E: Other Aspects}

- What special activities are you planning for the first week of the course?

- How will you inform students of the course program?

- What problems might arise in planning and holding the course?

- How will you deal with these problems?

- How will you assess your success in achieving the aims of the course?

- How will you assess your teaching in the course?

This method of course design helps develop students' deep knowledge contents. This approach makes it possible for students to improve their ability to search for and find information and contributes to the development of metacognitive abilities (Thompson \& Licklider, 2011). Although students don't always understand how and why they should be accountable for their learning (Wiersema \& Licklider, 2007) and are not necessarily inherently capable of extensive learning beyond acquiring knowledge (Wiersema \& Licklider, 2007), the purpose of backward design is to urge students to maximize their abilities and cause them to relinquish the position of passive recipients of knowledge.

The backward design approach is applied in the US, mainly in STEM disciplines as a result of the covert/overt assumption of policymakers that the scientific field is most worthy of educational investment as economic success is dependent on it. Indeed, the significance of STEM disciplines cannot be denied; however, the question is whether these fields are superior to others - for example, the humanities. We think not. We must strive for learning outcomes, not only in the STEM disciplines, but rather in all academic disciplines. 


\section{BACKWARD COURSE DESIGN - FROM STEM DISCIPLINES TO ALL ACADEMIC DISCIPLINES}

As stated, backward course design stems from the learning-centered paradigm which rather than asking students "What did you learn in order to complete the course?" asks "What do you know and what can you do now that you could not do previously prior to taking this course?" Therefore, the first step in course design is defining instruction goals: What will students know and be able to do, in general, by the end of the course? Once general goals have been defined, learning outcomes must be defined individually. The second step is to decide what significant learning achievements should be achieved by learners. Then, the third step is to choose a means of measuring achievement of the goals, while only the fourth and final step includes deciding how to teach in order to achieve the intended learning outcomes.

In order to demonstrate use of this method, let's take, for example, the course "The ethos of the Holocaust in the $21^{\text {st }}$ century: Dilemmas and challenges" composed in the learning-centered approach and taught by the author as part of a course given in POD (The Professional and Organizational Development Network in Higher Education). The purpose of the course and its general description were explained to students in the syllabus: "The course is based on several topics related to educational and moral aspects of the Holocaust and it includes reading material and classroom discussions on these topics. Students can also propose relevant materials from various disciplines relevant to the topic of the course that might enrich class discussions. All material chosen for this course offers unique perspectives on the topic studied." The vision of the instructor for students is that each student will add materials of his/her own to the course, reflecting a cognitive, emotional, or moral perspective on the topic of the Holocaust. The large goal of the course, which should be formulated in terms of the desired effect on students, was defined as the hope that the learning experience would become meaningful, affecting the lives of students, such that the topic of the Holocaust would become part of their agenda and another perspective through which they can observe their own lives and those of others.

In the first stage, general student-centered goals of the course were formulated. The course shall have an effect on students' lives and its topic will become part of their agenda. The learning experience shall give students a perspective that will make it possible for them to examine their own lives differently. In addition, aside from personal learning, the purpose of the course is to create a community committed to the subject of learning about the Holocaust.

In the second stage, individual (behavioral) goals were formulated, drawing from the general goals. The course will be considered a success if by its end students will be able to display the following skills: information gathering, evaluation and critique, categorization of materials (cognitive, emotional, and moral) for analysis and synthesis.

In the third stage, assessment methods (for measuring achievement of individual goals) were determined and criteria for assessing implementation were set. The method chosen was writing a composition on a selected topic. Each topic required the prior approval of the instructor. Each composition was assessed by the instructor. Success was defined as increasing student involvement in the subject studied - raising questions, presenting positions, confronting various issues - all these were identified as criteria for success of the learning process.

In the fourth stage, teaching methods/strategies for achieving these goals were chosen. In order to achieve the specific goals presented, the learning strategy chosen was to create a unique climate for the course, where students would feel comfortable engaging in the subject of the Holocaust on a cognitive, emotional, and moral level. In addition, another strategy adopted was self-efficacy. The purpose was to give students the feeling that they have the power to generate change, both for themselves and for others. Use of the course website made it possible to expand the time and space for learning about the subject. Online learning is particularly well suited to the universal nature of the Holocaust as a field of study.

\section{DISCUSSION AND CONCLUSION}

The unique role of the backward design instruction method begins with identification of the learning goals of the course rather than with the course material and contents. In order to identify goals, instructors must ask 
themselves: What must students know and be able to do by the end of the course? They must choose assessment methods and criteria for measuring implementation. According to these goals, a teaching method shall be chosen. Instructors must choose the best teaching method for them in order to achieve the learning goals, both regarding the material to be included in the course and regarding the instruction strategy, planning of the schedule, and syllabus design. Expanding use of the backward design approach to all academic disciplines shall enable students to personally benefit from an array of courses rather than only STEM courses. If course design will remain contentcentered, many disciplines will probably become irrelevant, as students will continue to leave as they arrived.

With the increase in accessible knowledge, instructors are required to bring with them added value. This is a complicated requirement that compels instructors to think "outside the box" to relinquish regular teaching patterns. From my experience with backward design, planning a course in this method undoubtedly requires extensive thinking, time, and effort, compared to designing a course in the traditional method. It is necessary to become acquainted with students, be prepared for changes, and plan well for each lesson. In backward design, there is no room for spontaneity. An instructor cannot come to class without self-examination of the goals and means to be used. This requires a big effort; however, such an effort makes it possible for the instructor to face students with a real honest answer to questions such as "How will this help me in life?" or "Why should I come to class?"

Nevertheless, the instructor's efforts are not enough. In order for deep meaningful change to occur in how instructors teach in academe, this must be reinforced by policymakers. In an academic environment where instructors' output equals the number of their scientific publications (research output), instructors have no incentive to make an effort and develop their teaching. The Council for Higher Education (CHE) also recognizes the significance of incentives versus teaching outcomes. In the council's budgeting model, teaching output relates to the number of undergraduate and graduate students in the school and the level of degrees awarded, calculated in an efficiency formula (Council for Higher Education, 2012). Despite the change in the budgeting model employed by the CHE, it is doubtful whether this can overcome the superior status of the research component and make faculty see efficient teaching as a type of academic output as well. For this purpose, there is need for a model that recognizes and appreciates learning-centered teaching, one that will enable instructors to devote time and energy to developing these aspects in their work.

\section{AUTHOR INFORMATION}

Dr. Nitza Davidovich currently serves in teaching and administrative positions at Ariel University and is Director of Academic Development \& Evaluation. Areas of interest include academic curriculum development, development of academic instruction, Holocaust awareness and Jewish identity, director of student exchange programs with Germany and Poland, preservation of the heritage of Jewish sects, and moral education. Academic administration includes leader of academic assessment process at the Ariel University on behalf of the CHE, initiation and development of national and international academic collaboration, curriculum development, and development of curricula for special-needs populations. E-mail: d.nitza@ariel.ac.il

\section{REFERENCES}

1. Barak, A. \& King, S. A. (2000). The two faces of the internet: Introduction to the special issue on the internet and sexuality. Cyber Psychology \& Behavior, 3, 517- 520.

2. $\quad$ Barr, R. B., \& Tagg. J. (1995). From teaching to learning. Change, 27, 13-25.

3. BrckaLorenz, A., Haeger, H., Nailos, J., \& Rabourn, K. (2013). Student perspectives on the importance and use of technology in learning. Paper presented at the Annual Forum of the Association for Institutional Research. Retrieved May 31 from: http://nsse.iub.edu/html/pubs.cfm?action=\&viewwhat=Conference \%20Paper,Conference\%20Presentation

4. Council for Higher Education (2012). Budgeting model for Israeli higher education. Retrieved on June 5, 2013, from: http://che.org.il/?page_id=994. [Hebrew].

5. Cross, K. P. (2000). Cross paper \#4: Collaborative learning 101. Mission Viejo, CA: League for Innovation in the Community College.

6. Daugherty, K. K. (2006). Backward course design: making the end the beginning. American Journal of Pharmaceutical Education, 70, 1-5. 
7. Davis, R. (1999). The Web of Politics, the Internet Impact on the American Political System. New York, Oxford: Oxford University Press.

8. Eberly, M. B., Newton, S. E., \& Wiggins, R. A. (2001). The syllabus as a tool for student-centered learning. The Journal of General Education, 50, 56-74.

9. Gehart, D. (2011). The core competencies and MFT education: Practical aspects of transitioning to a learning-centered, outcome-based pedagogy. Journal of Marital And Family Therapy, 37, 344-354.

10. Harari, Y. N. (2011). A Brief History of Mankind. Tel Aviv: Dvir. [Hebrew].

11. Harpe, S. E., Phipps, L. B., \& Alowayesh, M. S. (2012). Effects of a learning-centered approach to assessment on students' attitudes towards and knowledge of statistics. Currents in Pharmacy Teaching and Learning, 4, 247-255.

12. Internet World Stats (2013). Retrieved on May 31, 2013, from http://www.internetworldstats.com/stats.htm

13. Jones, S. (2002). The Internet Goes to College: How Students Are Living in the Future with Today's Technology. Pew Internet and American Life Project. September 15. http://books.google.co.il/books?id=FBtcMsRcRdwC\&printsec=frontcover\#v=onepage \&q\&f=false

14. Kazley, A. S., Annan, D. L., Carson, N. E., Freeland, M., Hodge, A. B., Seif, G. A., \& Zoller, J. S. (2013). Understanding the use of educational technology among faculty, staff, and students at a medical university.Tech Trends, 57, 63-70.

15. King, J. M., \& Anderson, D. M. (2004). A practitioner's guide to a learning-centered co-curricular activities program. College Student Affairs Journal, 24, 91-100.

16. Kuh, G. D., Kinzie, J., Schuh, J. H., \& Whitt, E. J. (2010). Student Success in College: Creating Conditions that Matter. Jossey-Bass.

17. Kuh, G. D., Schuh, J., Whitt, E., Andreas, R. E., Lyons, J. W., \& Strange, C. C. (1991). Involving Colleges. Successful Approaches to Fostering Student Learning \& Development Outside the Classroom. San Francisco: Jossey-Bass.

18. Kulik, J. A., Kulik, C. -L. C., \& Cohen, P. (1980). Effectiveness of computer-based college teaching: A meta-analysis of findings. Review of Educational Research, 50, 525-544.

19. McKeachie, W. J. (1990). Research on college teaching: The historical background. Journal of Educational Psychology, 82, 189-200.

20. McLuhan, M. (1964/1995). Hot medium and cold medium. In: D. Caspi (ed.), Trends and Traditions in Mass Communication: A Reader. Tel Aviv: Open University. [Hebrew].

21. Phipps, R., \& Merisotis, J. (1999). What's the difference? A review of contemporary research on the effectiveness of distance learning in higher education. Washington, DC: Institute for Higher Education Policy.

22. Postman, N. (1993). The Surrender of Culture to Technology. New York: Vintage Books.

23. Reynolds, J. (2000). Learning-centered learning: Theory into practice. Inquiry, 5, 1-9.

24. Rogoff, B. (1994). Developing an understanding of the idea of communities of learners. Mind, Culture, and Activity, 1, 209-229.

25. Seel, N. M. (2003). Model-centered learning and instruction. Technology, Instruction, Cognition and Learning, 1, 59-85.

26. Shinar, D. (2001). Internet: Communications, Society, and Culture. Tel Aviv: Open University. [Hebrew].

27. Stage, F. K., \& Muller, P. (1998). Creating learning-centered classrooms. What does learning theory have to say? ERIC Digest. Retrieved on May 30, 2013 from:

http://www.ydae.purdue.edu/lct/hbcu/documents/Creating_Learning_Centered_Classrooms_What_Does T heory_Say.pdf

28. Streveler, R. A., Smith, K. A., \& Pilotte, M. (2012). Aligning course content, assessment, and delivery: Creating a context for outcome-based education. In: K. Mohd Yusof, S. Mohammad, N. Ahmad Azli, M. Noor Hassan, A. Kosnin and S. K. Syed Yusof (Eds.), Outcome-Based Education and Engineering Curriculum: Evaluation, Assessment and Accreditation. Hershey, Pennsylvania: IGI Global.

29. Thompson, J. R. \& Licklider, B. L. (2011). Visualizing urban forestry: Using concept maps to assess student performance in a learning-centered classroom. Journal of Forestry, 109, 402-408.

30. Wagner, E. B., \& McCombs, B. L. (1995). Learner centered psychological principles in practice: Designs for distance education. Educational Technology, 35, 32-35.

31. Wiersema, J.A, \& Licklider, B.L (2007). Accountability for learning belongs to the learner. Higher Education in Review, 4, 43-61. 
32. Wiggins, G. \& McTighe, J. (2005). Understanding by Design: Expanded Second Edition. Alexandria, VA: ASCD. 